\title{
Türkiye'de yaşlı yetişkinlerin genel sağlık durumu görüşleri: cinsiyet farklılığı
}

\section{General health status opinions of older adults in turkey sample: gender differences}

\author{
Emre Baskan, Nesrin Yağcı, Uğur Cavlak, Mücahit Öztop
}

Gönderilme tarihi:17.06.2020

Kabul tarihi:10.07.2020

Özet

Amaç: Gittikçe artan yaşı nüfusunda sağlığı etkileyen faktörlerin bilinmesi olası risklerin önüne geçilmesi ve tedavisi açısından önemlidir. Çalışmamız yaşı ıetişkinlerde genel sağlık durumu ile ilgili görüşleri belirlemek ve cinsiyet farklılıklarını incelemek amacıyla planlanmıştır.

Gereç ve yöntem: Çalışmaya kognisyon düzeyi iyi olan (Hodkinson Mental Test 7 puan ve üzeri) 65-97 yaşları arasında toplam 278 (Erkek:158, Kadın:120) gönüllü yaşlı yetişkin dahil edildi. Hastalık Kontrol ve Önleme Merkezi (HKÖM-4) ölçeğinin ilk sorusu yaşı yetişkinlerin genel sağlık durumunu değerlendirmek için kullanıldı. Genel sağlık durumları mükemmel, çok iyi, iyi, ortalama ve kötü olarak sınıflandırılmaktadır. Açık uçlu sorular ile mevcut genel sağlık ve yaşam kalitesini etkileyen en önemli konuların ifade edilmesi istendi.

Bulgular: Çalışmaya katılan yaşlıların yaş ortalaması $71,74 \pm 5,54$ yıl $(K=71,12 \pm 5,29 \quad E=72,22 \pm 5,73)$ idi. Kadınlarda erkeklerden daha fazla kronik hastalık vardı $(p<0,05)$. Kendi ifadelerinden kadınların çok daha fazla ilaç kullandıkları $(p<0,05)$, artritik problemlere daha yatkın oldukları $(p=0,001)$ ve daha düşük egzersiz seviyesine $(p=0,0001)$ sahip olduklarını bulundu. Kadınlar genel sağlık durumlarını Ortalama $(\% 49,2)$ olarak tanımlarken, erkekler İyi $(\% 38,0)$ olarak tanımladı. Kendi ifadeleriyle en önemli sağlık sorunlarının hipertansiyon, artritik problemler ve diabetes mellitus olduğunu bulduk.

Sonuç: Bu çalışmada elde edilen sonuçlar yaşlı yetişkinlerin kendi sağlık durumlarının farkında olduğunu ve sağlık durumlarını ağırlıklı olarak Ortalama şeklinde tanımladıklarını göstermiştir. Kronik hastalıklar konusunda kadınlarda erkeklerden daha fazla hastalık bulunduğu ve kadınların daha az egzersiz yaptığı tespit edilmiştir.

Anahtar kelimeler: Kronik hastalık, sağlık durumu, yaşlı yetişkin.

Baskan E, Yagcı N, Cavlak U, Öztop M. Yaşlı yetişkinlerin genel sağlık durumu görüşleri: cinsiyet farklılığı. Pam Tip Derg 2021;14:71-77.

\section{Abstract}

Purpose: To know the factors affecting health in the increasingly elderly population is important in terms of preventing and treating possible risks. Our study was planned to determine the opinions about the general health status of elderly adults and to examine gender differences.

Materials and methods: In total, 278 elderly volunteers (Male: 158, Female:120), between 65-97 ages who has good cognitive function (Hodkinson Mental Score 7 and above) were enrolled in the study. The first question of the Disease Control and Prevention Center (CDC-4) scale was used to assess the overall health status of older adults. The general health status classified as excellent, very good, good, average and poor. The most important issues affecting the current general health and quality of life were asked to express by asking openended questions.

Results: The average age of elderly people participating in the study was $71.74 \pm 5.54$ years $(F=71.12 \pm 5.29$ $M=72.22 \pm 5.73)$. Women had more chronical diseases than man $(p<0.05)$. From their own expression, we found that women used much more drugs $(p<0.05)$, were more prone to arthritic problems $(p=0.001)$ and had a lower level of exercise $(p=0.0001)$. Women defined their health status like Average $(49.2 \%)$ while man defined as Good $(38.0 \%)$. We found that most important health problems by their expressions are, hypertension, arthritic problems and diabetes mellitus.

Conclusions: The results showed that older adults were aware of their own health status and define their health status predominantly as Average. Regarding chronic diseases, it is determined that women have more diseases than men and women exercise less.

Key words: Chronic disease, health status, older adults.

Emre Baskan, Dr. Öğr. Üye. Pamukkale Üniversitesi, Fizik Tedavi ve Rehabilitasyon Yüksekokulu, Denizli, Türkiye, e-posta: emrebaskan@ hotmail.com (orcid.org/0000-0001-7069-0658) (Sorumlu Yazar)

Nesrin Yağcı, Prof. Dr. Pamukkale Üniversitesi, Fizik Tedavi ve Rehabilitasyon Yüksekokulu, Denizli, Türkiye, e-posta: nesrinyagci@yahoo.com (orcid.org/0000-0002-5669-4932)

Uğur Cavlak, Prof. Dr. Trabzon Avrasya Üniversitesi, Sağlık Bilimleri Fakültesi, Fizyoterapi ve Rehabilitasyon Bölümü, Trabzon, Türkiye, e-posta: ucavlak@yahoo.com (orcid.org/0000-0002-5290-9107)

Mücahit Öztop, Uzm. Fzt. Pamukkale Üniversitesi, Fizik Tedavi ve Rehabilitasyon Yüksekokulu, Denizli, Türkiye, e-posta: mucahitoztop@gmail. com (orcid.org/0000-0002-9369-3381) 
Baskan E, Yagci N, Cavlak U, Oztop M. General health status opinions of older adults in Turkey sample: gender differences. Pam Med J 2021;14:71-77.

\section{Giriş}

Yaşlanma, döllenme ile başlayan ve yaşam boyu süren durdurulamaz anatomik ve fizyolojik değişiklikler sürecidir [1]. Bu süreç boyunca fiziksel ve ruhsal beceriler düşüş gösterir ve özre sebep olan sağlık problemlerinde, özellikle mobilite kısıtılıklarında artış gözlenir [2, 3]. Dünya Sağlık Örgütü (DSÖ) 2015 ve 2050 yılları arasında 60 yaş ve üzeri bireylerin dünya nüfusuna oranının \%12'den \%22'ye yükselerek yaklaşık ikiye katlanacağını bildirmiştir [4].

Sağlık alanındaki gelişmelere paralel olarak artan yaşı nüfusun sağlığının korunması için yapılacak koruyucu ve rehabilite edici çalışmaların önemi artmıştır [5, 6]. Bu bağlamda sağlığın korunması için sağlığı etkileyen değişimlerin tanımlanması gereklidir.

Pek çok çalışmada; yaşlı bireylerde azalmış fonksiyonel kapasite ve günlük yaşam aktivitelerinde bağımlılık, multiple patoloji sayısındaki artış ve polifarmasiyi ortaya koymuştur [7, 8]. Ayrıca yaşlı bireyin sosyal katılımlarının da genel sağlık durumu ile ilişkili olduğu belirlenmiştir [9].

Yaşlılarda daha sık görülen sağlık problemleri kronik ve dejeneratif hastalıklardır. Bunlar kas-iskelet, kardiyovasküler, boşaltım ve sinir sistemlerine ek olarak kognitif fonksiyonları da etkileyen hastalıklardır $[10,11]$. Ayrıca Roh ve ark. [12] tarafından yapılan bir araştırma üst ve alt ekstremite özürlerinin yaşlılarda algılanan genel fiziksel sağlık ile ilişkili olduğunu fakat algılanan genel mental sağlığın sadece üst ekstremite özürlerinden etkilendiğini göstermiştir. Kas-iskelet problemlerinin ilerleyen yaşla artış gösterdiği de kanıtlanmıştır [13]. Tüm bu bilgilere ek olarak kadın cinsiyetin depresif semptomlar ve bozukluklarla ilişkili olduğu ve yaşlı kadınların yaşam kalitesinin yaşlı erkeklere oranla daha düşük olduğu belirlenmiştir [14-16].

Bu çalışmanın amacı yaşııların genel sağlık durumlarını incelemek ve cinsiyet farklııklarını ortaya koymaktır.

\section{Gereç ve yöntem}

Çalışmamı kesitsel ve tanımlayıcı bir çalışma olup, evreni Denizli ili Merkez
Efendi İlçesinde ikamet eden, ev ortamında yaşayan, kognitif düzeyi iyi olan $65-85$ yaşları arasındaki yaşlı katılımcılardan oluşturulmuştur $(n=3052)$. Çalışma örneklemi için yapılan güç analizi sonucunda, çalışmaya en az 278 yaşlı alındığında \%95 güven aralığında $\% 80$ güç elde edileceği hesaplanmıştır. Veriler Türkiye İstatistik Kurumu web sayfasından alınmıştır. Çalışmamız Helsinki Deklerasyonu ilkelerine uygun şekilde yürütülmüş ve Pamukkale Üniversitesi Girişimsel Olmayan Klinik Araştırmalar Etik Kurulu'nca onaylanmıştır. Çalışmamızda araştırma ve yayın etiğine uyulmuştur. Veri toplama formları uygulanmadan önce çalışmaya katılmaya gönüllü olan yaşlı katıımcılara tanıtıImıştır. Araştırmanın amacı ile ilgili bilgi verilmiş ve yazılı onamları alınmıştır. Katılımcılara önce Hodkinson Mental Test (HMT) uygulanmıştır. Bu testten 7 puan ve üzeri alan yaşlı katıımcılar çalışmaya dâhil edilmiştir [17, 18]. Ambulasyonu engelleyecek sağlık problemi bulunan yaşılıar çalışmaya alınmamıştır.

Yaşlılılar ile görüşmeler ve veri toplama işlemleri yüz yüze görüşme yöntemi kullanılarak yapılmıştır. Katılımcıların sosyo-demografik özellikleri (medeni durumu, eğitim düzeyi, sigara ve ilaç kullanımı) ayrıca egzersiz alışkanlıkları ile ilgili bilgiler sorgulanarak kayedilmiştir.

Katıımcılara genel sağlık düzeylerini en çok etkileyen 5 sağlık sorununu yazmaları istenen bir açık uçlu soru sorulmuştur.

Tüm katıııcıların genel sağlık durumu Hastalık Kontrol ve Önleme Merkezi (HKÖM4) ölçeğinin ilk sorusu ile sorgulanmıştır [19]. Bu kapsamda katııımcılara "sağlık düzeyinizi nasıl tanımlarsınız" sorusuna mükemmel, çok iyi, iyi, orta, kötü şeklinde beş cevap seçeneği sunulmuştur.

İstatistiksel analizlerde "SPSS 22,0 for Windows" istatistik programı kullanılmıştır. Tanımlayıcı istatistiklerden ortalama \pm standart

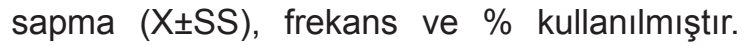
Demografik veri analizlerinde Ki-kare testi, cinsiyetler arası sağlık sorunlarının karşılaştırmalarında ise Bağımsız Örneklemlerde t Testi kullanılmıştır. Anlamlılık düzeyi $p<0,05$ olarak kabul edilmiştir. 


\section{Bulgular}

Çalışmaya yaş ortalaması $71,7 \pm 5,54$ yıl olan ev ortamında yaşayan 158 erkek, 120 kadın toplam 278 gönüllü yaşı katılımcı dâhil edilmiştir. Katılımcıların \%64,5'i evli, \%17,7'si 8 yıl ve üzeri eğitime sahip olduğunu, \%49,3'ü günde 3 ve üzeri ilaç kullandığını, \%64'ü egzersiz alışkanlığı olduğunu ve \%95,7'si sağlık sigortalarının olduğunu bildirmişlerdir (Tablo 1).

Çalışmamıza katılan yaşılıarın \%42,4'ü genel sağlık düzeyini "Orta" olarak tanımlamaktadır. Cinsiyet dağılımı Grafik 1'de gösterilmiştir. Kadın yaşıların büyük çoğunluğu $(\% 49,2)$ genel sağlık düzeylerini "orta" olarak belirtirken, erkek yaşlıların büyük çoğunluğu (\%38) "iyi” olarak tarif etmişlerdir.

Yaşlıları en fazla etkileyen sağlık sorunları incelendiğinde ilk sırayı \%32,4 ile hipertansiyon probleminin aldığı, kadın yaşılıarda ise en önemli sağlık sorunlarının \%34,2 ile hipertansiyon ve eklem artrozları olduğu tespit edilmiştir. Cinsiyetler arasında en fazla sorun yaşadıkları sağlık sorunları karşılaştııılı̆̆ında eklem artrozları, diabetes mellitus ve spinal ağrılardan kadınların erkeklere göre daha fazla etkilendikleri tespit edilmiştir $(p<0,05)$. Kadınlarda erkeklerden daha fazla kronik hastalık tespit edildi $(p<0,05)$ (Tablo 2$)$.

\section{Tartışma}

Yaşlılarda genel sağlık durumlarını incelemek ve cinsiyetler arasındaki farklıığı saptamak amacıyla yapılan bu çalışmada egzersiz alışkanlığından mevcut kronik hastalıklara ve cinsiyetin bu durumlar üzerindeki etkileri ile ilgili değerli sonuçlar tespit edilmiştir. Çalışmamıza katılan yaşı katııımılar genel sağlık durumlarını ağırlıklı olarak orta düzeyde olduğunu bildirmişlerdir. Genel sağlık düzeylerinde cinsiyetler arası fark anlamsız iken, yaşanılan sağlık sorunları açısından fark kadınlar lehine anlamlı olarak bulunmuştur.

Hipertansiyon, özellikle yaşlıarda kardiyovasküler morbidite ve mortalite için önemli bir risk faktörüdür ve prevelansı 6079 yaşları arasındaki kadınlarda artmaktadır [20]. Çalışmamızda katılımcıların \%32,4'ünde hipertansiyon varlığı tespitedilmiştirve cinsiyetler arasında herhangi bir fark bulunmamıştır.

Tablo 1. Katılımcıların sosyo-demografik ve klinik verileri

\begin{tabular}{|c|c|c|c|c|}
\hline Değişkenler & $\begin{array}{l}\text { Genel } \\
\overline{\mathbf{x}}(\mathrm{SS})\end{array}$ & $\begin{array}{l}\text { Erkek }(n=158) \\
\bar{x}(S S)\end{array}$ & $\begin{array}{l}\text { Kadın }(n=120) \\
\bar{x}(S S)\end{array}$ & $p$ \\
\hline Yaş (yıl) * & $71,4(5,54)$ & $72,22(5,73)$ & $71,12(5,23)$ & $>0,05$ \\
\hline VKI $\left(\mathrm{kg} / \mathrm{cm}^{2}\right)^{*}$ & $28,16(5,08)$ & $27,43(4,77)$ & $29,13(5,33)$ & 0,005 \\
\hline HAMT (skor) ${ }^{*}$ & $\begin{array}{l}8,85(1,0) \\
n(\%)\end{array}$ & $\begin{array}{l}9,20(0,85) \\
n(\%)\end{array}$ & $\begin{array}{l}8,39(1,01) \\
\mathrm{n}(\%)\end{array}$ & 0,0001 \\
\hline $\begin{array}{r}\text { İlaç Alımı (Sayı) } \\
\text { Yok } \\
1 \\
2 \\
3 \text { ve }\end{array}$ & $\begin{array}{l}50(18) \\
39(14) \\
52(18,7) \\
137(49,3)\end{array}$ & $\begin{array}{l}37(23,4) \\
25(15,8) \\
28(17,7) \\
68(43)\end{array}$ & $\begin{array}{l}3(10,8) \\
14(11,7) \\
24(20) \\
69(57,5)\end{array}$ & 0,019 \\
\hline $\begin{array}{l}\text { Eğitim ** } \\
\text { Okur-yazar değil } \\
1-8 \text { yıl }\end{array}$ & $\begin{array}{l}79(28,5) \\
149(53,8) \\
49(17,7)\end{array}$ & $\begin{array}{l}26(16,6) \\
96(61,1) \\
35(22,3)\end{array}$ & $\begin{array}{l}53(44,2) \\
53(44,2) \\
14(11,7)\end{array}$ & 0,0001 \\
\hline $\begin{array}{c}8 \text { yıl } \\
\text { Egzersiz ** }\end{array}$ & $\begin{array}{l}178(64) \\
100(36)\end{array}$ & $\begin{array}{r}116(73,4) \\
42(26,6)\end{array}$ & $\begin{array}{l}62(51,7) \\
58(48,3)\end{array}$ & 0,0001 \\
\hline $\begin{array}{r}\text { Yok } \\
\text { Sağlık Sigortası ** } \\
\text { Var } \\
\text { Yok }\end{array}$ & $\begin{array}{c}266(95,7) \\
12(4,3)\end{array}$ & $\begin{array}{c}154(97,5) \\
4(2,5)\end{array}$ & $\begin{array}{l}112(93,3) \\
8(6,7)\end{array}$ & $>0,05$ \\
\hline
\end{tabular}

$\overline{\mathbf{x}}$ : Ortalama SS: Standart Sapma; VKI: Vücut Kütle İndeksi; HAMT: Hodkinson's Abbreviated Mental Test;

*: İki Bağımsız Örneklemde t-Test; **: Ki-Kare Test 


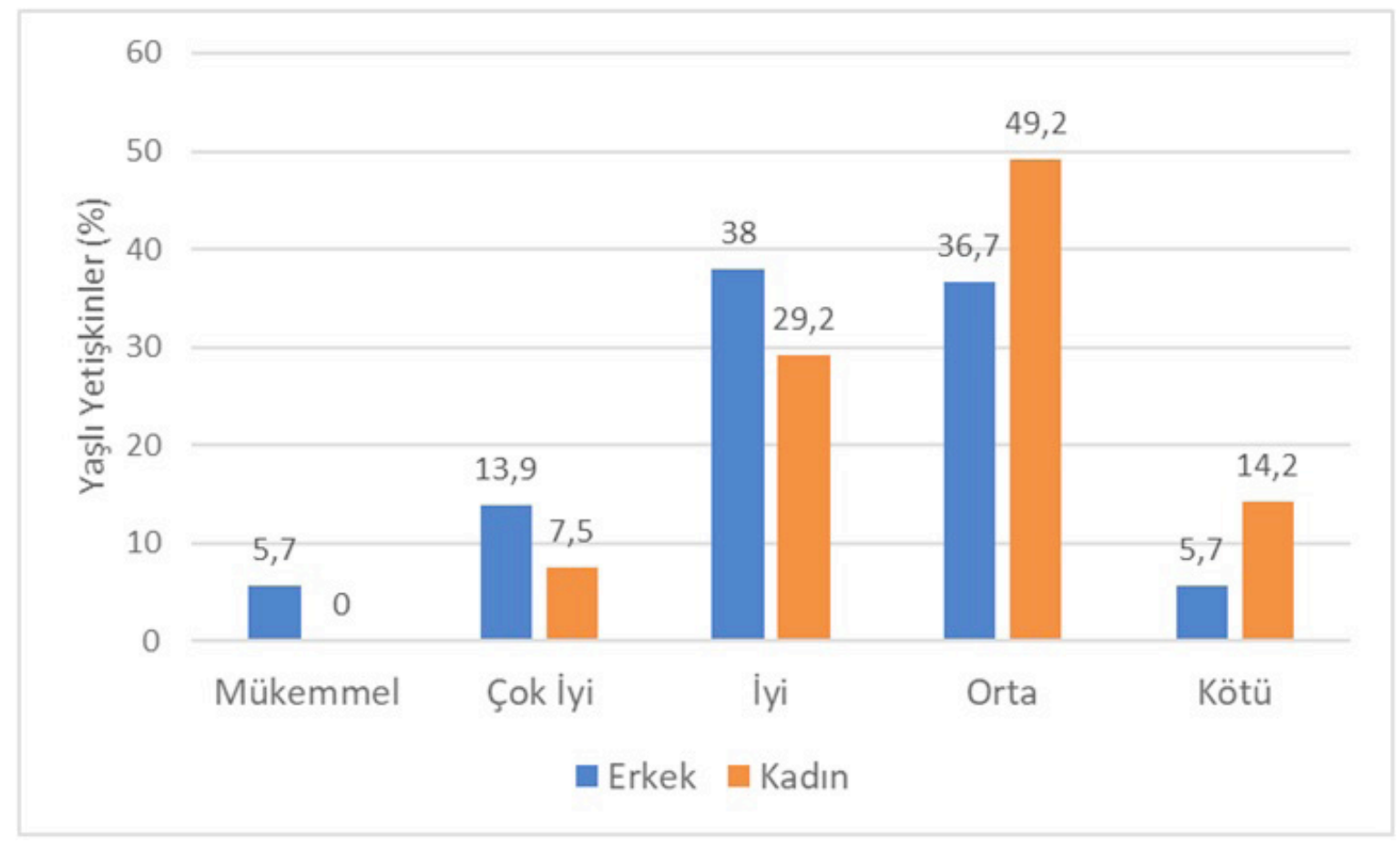

Grafik 1. Genel sağlık durumunun cinsiyetlere göre dağılımı

*: İki bağımsız örneklemde t-test

Tablo 2. Katılımcılara ait sağlık problemleri dağılımı

\begin{tabular}{lclll}
\hline Kronik Sağlık Problemleri & $\begin{array}{c}\text { Total } \\
\mathbf{n}(\mathbf{\%})\end{array}$ & $\begin{array}{l}\text { Erkek (n=158) } \\
\mathbf{n}(\mathbf{\%})\end{array}$ & $\begin{array}{l}\text { Kadın (n=120) } \\
\mathbf{n}(\mathbf{\%})\end{array}$ & $p$ \\
\hline Hipertansiyon & $90(32,4)$ & $49(31)$ & $41(34,2)$ & 0,461 \\
Eklem Artrozu* $_{\text {Diabetes Mellitus* }}$ & $65(23,4)$ & $24(15,2)$ & $41(34,2)$ & $\mathbf{0 , 0 0 1}$ \\
Kalp-Damar Hastalıkları & $61(21,9)$ & $23(14,6)$ & $38(31,7)$ & $\mathbf{0 , 0 0 4}$ \\
Spinal Ağrılar* & $51(18,3)$ & $25(15,8)$ & $26(21,7)$ & 0,454 \\
& $35(12,6)$ & $14(8,9)$ & $21(17,5)$ & $\mathbf{0 , 0 3 5}$ \\
\hline
\end{tabular}

Yaşıllarda kas-iskelet ağrısı yaygın görülür ve özre sebep olabilir. Osteoartrit, inflamatuar artrit, tendinit ve bursit gibi yumuşak doku problemleri de dahil olmak üzere romatizmal ağrıya neden olan koşullar, çoğunlukla tedavi edilemez olduğundan, yaşam kalitesini korumak için ağrı kontrolü çok önemlidir [21]. Çalışmamıza katılan yaşılıarda \%23,4 oranında artroz varlığı tespit edilirken, kadınlarda anlamlı bir şekilde daha fazla olduğu görülmüştür. Aynı zamanda kadın vakalardaki yüksek beden kitle endeksi, artroz görülme sıklığı açısından dramatiktir.

İnsüline bağımlı diabetes mellituslu (DM) yaşılıarda eklem hareket açıkığı azalmaktadır. Buna neden olarak kollajenin enzimatik olmayan ileri glikasyon son ürünleri oluşumu ile çapraz bağlanmasını arttırdığı belirtilmektedir [22]. Çalışmamızda katılımcılarda \%21,9 oranında DM tespit edilmiş olup kadın yaşlılarda bu oranın daha yüksek olduğu görülmüştür. Yine artrit oranındaki bağlantıya benzer, kadınlardaki vücut kitle oranının yüksekliği ile diyabet görülme sıklığı birbirine paralel seyretmektedir. Her iki cinsiyette de yüzdesel olarak polifarmasiye yatkınlık tespit edilmesi katılımcıların çoğunun kronik hastalıkla mücadele ettiğini düşündürmektedir.

Yaşılıarda kas-iskelet ağrıları, önemli sakatlık ve sağlık maliyetine sebebiyet verir. Boyun ve sırt ağrısı en yaygın bölgesel kasiskelet hastalığıdır [23-25]. Murata ve ark. [24] gerçekleştirdikleri çalışmada yaşılıarda bel ağrısı görülme sıklığını \%34,5 ve boyun ağrısı için ise $\% 6,0$ olarak tespit etmişlerdir. Çiçekçi ve ark. [25] tarafından Türkiye'de gerçekleştirilen bir çalışmada ise bu değerler bel ağrısı için $\% 51,2$ ve boyun için $\% 24,1$ şeklindedir. Çalışmamıza dahil olan katıımcılarda tespit 
edilen spinal ağrı problemleri \%12,6 olarak bulunmuştur. Literatürde görülen sonuçlara benzerdir. Çalışmalarda bu problemlerin kadın yaşlılarda daha fazla görüldüğü ve bunun nedeninin de düşük eğitim seviyesi, daha az kas kitlesi, hormonal ve biyolojik farklılıkların sonucu olduğu söylenmektedir [2to pinpoint the factors affecting the pain and to research their effect on patients' quality of life. Methods: 203 patients over 65 who came to our Physical Therapy and Rehabilitation clinic were included in the study. Intensity of comorbid diseases were calculated by using Cumulative Illness Rating Scale (CIRS5]. Çalışmamızda da diğer hastalıklarda olduğu gibi kadın yaşılıarda bu oran yüksek bulunmuştur. Biz de bunun nedeninin kadınların daha yüksek VKI'ye sahip olması, daha düşük eğitim düzeyine ve egzersiz alışkanlığına sahip olmalarına bağlamaktayız.

Li ve ark. [26] gerçekleştirdikleri çalışmada yaşlı erkeklerin kadınlara oranla daha fazla günlük adım attıklarını ve şiddetli, düşük şiddetli fiziksel aktivitelere kadınlardan daha çok katıldıklarını ifade etmiştir. Özellikle erkek katıımcılardaki egzersiz alışkanlığının kadınlara oranla anlamlı olarak daha yüksek çıkması, beden kitle endeksinde azalma ve buna bağlı oluşabilecek artrit, diabet ve spinal ağrı gibi hastalıkların görülme oranında azalmaya sebebiyet verdiğini düşünmekteyiz.

Yapılan çalışmalarda yaşlıların genel sağlık düzeyleri incelenmiş ve erkeklerin $\% 47,77$ ve kadınların ise \%53,11 oranında kendi sağlık düzeylerinin kötü olduğunu düşündüklerini ifade etmiştir [27]. Bir diğer çalışmada ise veriler verilmemekle beraber Barile ve ark. [28] kadınların erkeklere göre daha yüksek oranda mental ve fiziksel iyilik halinde olduklarını ifade etmiştir. Çalışmamızda ise tüm katılımcıların genel sağlık durumları orta ve iyi düzeyde bulunmuştur. Literatürle benzer şekilde kadın katılımcıların büyük çoğunluğu kendi sağlık durumlarını orta düzeyde olduğunu belirtirken, erkek katılımcılar ise sağlık durumlarının iyi düzeyde olduğunu bildirmişlerdir. Aradaki bu farklılık için kadın katılımcılardaki sistemik problemlerin fazlalığına ve sağlık durumları hakkında daha fazla endişelendikleri için temkinli yanıtlar verdikleri söylenebilir. Ayrıca kadın katılımcılarda egzersiz alışkanlıklarının ve eğitim seviyelerinin oranı erkek katılımcılara göre daha düşük olmasının da sağlık durumlarını etkilemiş olabileceği düşüncesindeyiz.

Sonuç olarak, bu çalışmada elde edilen veriler yaşlı yetişkinlerin kendi sağlık durumlarının farkında olduğunu ve sağlık durumlarını ağırlıklı olarak Ortalama şeklinde tanımladıklarını göstermiştir. Kronik hastalıklar konusunda kadınlarda erkeklerden daha fazla hastalık bulunduğu ve kadınların daha az egzersiz yaptığı tespit edilmiştir.

Yaşlılarda tespit ettiğimiz sağlık problemleri değiştirilebilir risk faktörleri açısından önemlidir. Egzersiz alışkanlığının kazandırılması, vücut farkındalıklarının artırııması yaşıırda görülebilecek kronik hastalık riskini azaltacaktır. Özellikle kadınlarda daha fazla görülen artrit, diabet, spinal ağrı gibi problemler halk sağlığı açısından dikkate değerdir. Kadınların toplumda istihdamının arttırıması, eğitim seviyesinin yükseltilmesi, egzersiz alışkanlığının kazandıııması onların sağlığı algılama ve koruma ile ilişkili yaşam biçimine olumlu yönde etki edecektir. Alınacak tedbirlerle yaşlılarda kronik hastalığa yakalanma sayısında azalma ve bu hastalıklar için harcanan devlet ve sigorta bütçelerine de olumlu yönden katkı sağlayacaktır.

Çalışmamızın güçlü yanı yaşlı katıımcıların kendi ifadeleri ile sağlık sorunlarını ve genel sağlık düzeylerini belirlemiş olmalarıdır. Bu durum aynı zamanda yaşlıların kendi sağlık problemlerinin ve sağlık düzeylerinin farkında olduklarını göstermesi açısından önemli sonuçlar vermiştir.

Çalışmamızın sadece Denizli ilinin bir ilçesindeki yaşlıları temsil etmesi limitasyon olarak kabul edilebilir ancak, sonuçlarımızın ileride planlanacak çalışmalara yol gösterici olduğunu düşünüyoruz. Bundan sonraki çalışmalarda evren büyüklüğünün daha geniş planlanması daha kesin sonuçlar vermesi bakımından önemli olacaktır.

Çıkar ilişkisi: Bu makalenin araştırması, yazarı ve / veya yayınlanması ile ilgili potansiyel bir çıkar çatışması beyan etmiyoruz.

\section{Kaynaklar}

1. Demirsoy A. Yaşlanmanın ve ölümün evrimsel öyküsü. Geriatri 1998;1:1-12

2. Koptagel İlal G. Yaşlılıkta psikosomatik hastalıklar. Noro Psikiyatr Ars 1992;29:3-14. 
3. Leveille SG, Ling S, Hochberg MC, et al. Widespread musculoskeletal pain and the progression of disability in older disabled women. Ann Intern Med 2001;135:10381046. https://doi.org/10.7326/0003-4819-135-12200112180-00007

4. World Health Organization. World report on ageing and health. 2015 Available at: https://apps.who.int/iris/ bitstream/handle/10665/186463/9789240694811_eng. pdf;jsessionid=3E1F685EF3B8BBD031D7F3702DA6 FE9F?sequence=1. Accessed 22 Mayıs 2020

5. Murayama L, Ahmed I. The geriatric patient. In: Handbook of consultation-liaison psychiatry. $2^{\text {nd }}$ Edition, Springer, Boston, MA, 2007:341-360. https:// doi.org/10.1007/978-0-387-69255-5_25

6. Yavuz BB. Geriatrik değerlendirme ve testler. İç Hastalıkları Dergisi 2007;14:5-17.

7. Danneskiold SamsØe B, Kofod V, Munter J, Grimby G, Schnohr P, Jensen G. Muscle strength and functional capacity in 78-81-year-old men and women. Eur J Appl Physiol Occup Physiol 1984;52:310-314. https://doi.org/10.1007/BF01015216

8. Hajjar ER, Cafiero AC, Hanlon JT. Polypharmacy in elderly patients. Am J Geriatr Pharmacother 2007;5:345351. https://doi.org/10.1016/j.amjopharm.2007.12.002

9. Savaş S, Akçiçek F. Comprehensive geriatric assessment. Ege Journal of Medicine Suppl 2010;49:19-30.

10. Larson EB, Reifler BV, Featherstone HJ, English DR. Dementia in elderly outpatients: a prospective study. Ann Intern Med 1984;100:417-423. https://doi. org/10.7326/0003-4819-100-3-417

11. Salgado R, Lord SR, Packer J, Ehrlich F. Factors associated with falling in elderly hospital patients. Gerontology 1994;40:325-331. https://doi. org/10.1159/000213607

12. Roh YH, Kim KW, Paik NJ, Kim TK, Gong HS. How much are upper or lower extremity disabilities associated with general health status in the elderly?. Clin Orthop Relat Res 2012;470:3246-3252. https:// doi.org/10.1007/s11999-012-2417-1

13. Lawrence RC, Felson DT, Helmick CG, et al. Estimates of the prevalence of arthritis and other rheumatic conditions in the United States. Part II. Arthritis Rheum 2008;58:26-35. https://doi.org/10.1002/art.23176

14. Orfila F, Ferrer M, Lamarca R, Tebe C, Domingo Salvany A, Alonso J. Gender differences in health-related quality of life among the elderly: the role of objective functional capacity and chronic conditions. Soc Sci Med 2006;63:2367-2380. https://doi.org/10.1016/j. socscimed.2006.06.017

15. Djernes JK. Prevalence and predictors of depression in populations of elderly: a review. Acta Psychiatr Scand 2006;113:372-387. https://doi.org/10.1111/j.16000447.2006.00770.x
16. Yağcı N, Telci EA. Yaşlılarda cinsiyetin genel sağlık durumuna, kognitif fonksiyona, depresif semptomlara, bel ve boyun ağrısına etkisinin incelenmesi: Denizli örneği. Yaşlı Sorunları Araştırma Dergisi 2016;9:53-60. Erişim adresi: https://atif.sobiad.com/index.jsp? modul=makalegoruntule\&id=AWCu6KPooDuH9Br_eFwu. Erişim tarihi 24 Haziran 2016

17. Hodkinson HM. Evaluation of a mental test score for assessment of mental impairment in the elderly. Age Ageing 1972;1:233-238. https://doi.org/10.1093/ ageing/1.4.233

18. Sarasqueta C, Bergareche A, Arce A, et al. The validity of Hodkinson's abbreviated mental test for dementia screening in Guipuzcoa, Spain. Eur J Neurol-2001;8:435-440. https://doi.org/10.1046/j.14681331.2001.00246.x

19. Lohr KN. Assessing health status and qualityof-life instruments: attributes and review criteria. Qual Life Res 2002;11:193-205. https://doi. org/10.1023/A:1015291021312

20. Lionakis N, Mendrinos D, Sanidas E, Favatas G, Georgopoulou M. Hypertension in the elderly. World J Cardiol 2012;4:135-147. https://doi.org/10.4330/wjc. v4.i5.135

21. Fitzcharles MA, Lussier D, Shir Y. Management of chronic arthritis pain in the elderly. Drugs Aging 2010;27:471-490. https://doi.org/10.2165/11536530000000000-00000

22. Abate M, Schiavone C, Pelotti P, Salini V. Limited joint mobility (LJM) in elderly subjects with type II diabetes mellitus. Arch Gerontol Geriatr 2011;53:135-140. https://doi.org/10.1016/j.archger.2010.09.011

23. Docking RE, Fleming J, Brayne C, Zhao J, Macfarlane GJ, Jones GT. Cambridge city over-75s cohort study collaboration. Epidemiology of back pain in older adults: prevalence and risk factors for back pain onset. Rheumatology 2011;50:1645-1653. https://doi. org/10.1093/rheumatology/ker175

24. Murata S, Doi T, Sawa R, et al. Association between objectively measured physical activity and the number of chronic musculoskeletal pain sites in communitydwelling older adults. Pain Med 2019;20:717-723. https://doi.org/10.1093/pm/pny112

25. Cicekci E, Ozisler Z, Ozel S, Unsal Delialioglu S, Ozisler C. The factors of musculoskeletal pain in geriatric patients and the relationship between pain and quality of life. Int J Clin Med 2017;08:504-513. https://doi.org/10.4236/ijcm.2017.88047

26. Li W, Procter-Gray E, Churchill L, et al. Gender and age differences in levels, types and locations of physical activity among older adults living in car-dependent neighborhoods. J Frailty Aging 2017;6:129-135. https:/ doi.org/ 10.14283/jfa.2017.15 
27. Gu D, Dupre ME, Warner DF, Zeng Y. Changing health status and health expectancies among older adults in China: gender differences from 1992 to 2002. Soc Sci Med 2009;68:2170-2179. https://doi.org/10.1016/j. socscimed.2009.03.031

28. Barile JP, Horner Johnson W, Krahn G, et al. Measurement characteristics for two health-related quality of life measures in older adults: The SF36 and the CDC Healthy Days items. Disabil Health J 2016;9:567-574. https://doi.org/10.1016/j. dhjo.2016.04.008

Bu çalışma 5-7 Ekim 2016 tarihinde LizbonPortekiz'de yapılan 12. EUGMS (Avrupa Birliği Geriatrik Tıp Derneği) Kongresinde poster olarak sunulmuştur.

Etik kurul onayı: Çalışmamı Pamukkale Üniversitesi Girişimsel olmayan Klinik Araştırmalar Etik Kurulu tarafından 19.02.2020 tarih ve 15175 sayı ilei toplantıda onaylanmıştır.

\section{Yazarların makaleye olan katkıları}

Çalışmanın konsepti ve dizaynı: U.C., N.Y.

Verilerin toplanması ve işlenmesi: E.B., M.Ö.

Verilerin analizi ve yorumlanması: E.B., N.Y.

Literatür araştırması: M.Ö.

Makalenin yazımı: N.Y., E.B., M.Ö.

Kritik gözden geçirme: E.B., N.Y., U.C., M.Ö.

Yayınlanacak versiyonun nihai onayı: E.B., N.Y., U.C. 